\title{
Cholestasis in Newborn
}

\author{
Paula Cristhina Niz Xavier ${ }^{\mathrm{a}, \mathrm{d}}$, Almir Sousa Martins ${ }^{\mathrm{b}}$, \\ Durval Batista Palhares ${ }^{c}$
}

\begin{abstract}
Cytomegalovirus (CMV) is one of the most important intrauterine infections that cause birth defects in humans with hematogenous transmission rate of $0.5 \%$ to $2.5 \%$, on average. The early transmission of infection from mother to fetus decreases the prognosis and increases the chances of serious anomalies. The objective of this case report is to instruct the neonatologist that despite the rarity of neonatal cholestasis, this may be a case of intrahepatic cholestasis resulting from congenital cytomegalovirus infection. This study aims to report the case of a 28 weeks and 6 days old child, presenting $1080 \mathrm{~g}$ birth weight, Apgar score 5 and 8, untreated sepsis, thrombocytopenia, leukocytosis, and jaundice with predominance in the evolution of direct bilirubin. To find out the cause of jaundice, serum bilirubin levels, serology and PCR (polymerase chain reaction) were performed for cytomegalovirus. Serology for cytomegalovirus was negative in spite of the molecular analysis by PCR in urine samples having demonstrated consistent results with the identification of genomic sequences of cytomegalovirus. Bilirubin values were: Total $15.58 \mathrm{mg} \%$; Direct $12.36 \mathrm{mg} \%$. It was concluded that treatment with ganciclovir resulted in satisfactory clinical response to treatment of cholestatic jaundice source cytomegalovirus.
\end{abstract}

Keywords: Neonatal cholestasis; CMV; Congenital infection; Herpes virus

\section{Introduction}

Congenital cytomegalovirus infection (CMV) is a common

Manuscript accepted for publication May 16, 2013

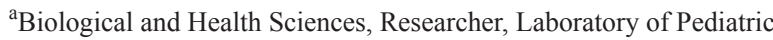
Research, University Hospital-UFMS, Campo Grande-MS, Brazil

${ }^{\mathrm{b}}$ Molecular Biology, Laboratory of General Physiology and Functional Genomics-(UFMG), Belo Horizonte-MG, Brazil

${ }^{c}$ Pediatrics Full Professor, MD, PhD, UFMS, Campo Grande, Brazil

${ }^{\mathrm{d}}$ Corresponding author: Paula Cristhina Niz Xavier. Av.: Senador

Filinto Muller-Vila Ipiranga. Laboratorio de Pesquisas Pediatricas. Departamento de Pediatria. CEP: 79080-190. Campo Grande, Mato Grosso do Sul, MS, Brazil. Email: paula.xavier@ufms.br

doi: http://dx.doi.org/10.4021/jmc1320w cause of congenital viral infection in developed countries and a major cause of hearing loss, as well as an important contributor to neurodevelopmental disabilities in children. The prevalence of congenital disease in different countries varies, but is usually between 0.15 to $2.0 \%$ [1]. The fetus and the newborn can be infected by the virus by placental transmission through blood and cervical secretions or breast milk, and the risk of fetal infection primary, higher than in maternal reinfection. CMV infections acquired during birth or through breast milk, which has no effect on future neurological development in infants at term [2]. However, premature infants less than 32 weeks gestational age, and may have symptoms similar to sepsis.

Fetal infection can be diagnosed by serology, amniotic fluid research, using viral culture and the identification of CMV-DNA analysis by polymerase chain reaction (PCR) using blood or urine.

The test-CMV IgG avidity is also a useful tool as a confirmatory method, dating the time of primary infection by CMV. Namely, IgM maternal not be transferred through the placenta, whereas IgG antibodies in the infant are mostly transferred maternal antibodies. The demonstration of serum IgM in the newborn before 2 and 3 weeks of age, is indicative of congenital infection. However, only $70 \%$ of neonates with congenital CMV have IgM antibodies at birth [3].

The avidity test is a measure of antibody binding CMVIgG. Early in infection the binding capacity is low, but over time, it increases. The investigation of maternal $\mathrm{IgG}$ avidity informs when the infection may have occurred. A high viral load in the amniotic fluid correlates with the fetal damage [1-4].

CMV is transmitted by direct contact between people through contact with urine, saliva, semen, cervical secretions and breast milk [4].

The congenital CMV infection in children can result in a number of deficiencies, alone or in combination, such as mental retardation, autism, learning disabilities, cerebral palsy, epilepsy, deafness or hearing impairment, visual impairment or blindness. Hearing loss can be late onset, during the first six years of life in children with both symptomatic and asymptomatic infection in the neonatal period $[1,5]$.

Studies evaluating the treatment pre-and postnatal con- 
genital CMV infection have shown encouraging clinical results for administration of ganciclovir [6-10]. In several case reports, both intravenously and by mouth, valganciclovir has been shown safe and effective for use in mothers with fetuses infected in the early stages of pregnancy without teratogenicity [11]. However, the safety and efficacy of ganciclovir in prenatal therapy should be further evaluated by means of clinical trials. A randomized controlled trial with ganciclovir showed that six weeks of intravenous treatment of ganciclovir $12 \mathrm{mg} / \mathrm{kg} /$ day beginning soon after birth in infants infected with CMV, with CNS involvement can preserved hearing [6].

\section{Case Report}

Child born at 28 weeks and 6 days [12], with birth weight of 1,080 grams, Apgar scores of 5 and 8 at one and five minutes respectively, regular prenatal consultations with 5, all negative serology, premature rupture of membranes $(\mathrm{PROM})>$ 40 hours, and a mother with a history of urinary tract infection in the last trimester of pregnancy and no regular treatment. Child was endotracheal intubation shortly after birth and maintained on mechanical ventilation throughout evolution to date November 23, 2012, when it was referred to a case. Three blood cultures were negative and that was evidenced Stahylococcus epidermidis, with 16 days of life. For evaluation, 12 blood samples to perform complete blood counts, and 10 of them showed leukocytosis ranging from 12,100 to $43,560 / \mathrm{mm}^{3}$ and most with bastonetose.

Of the $12 \mathrm{CBCs}, 4$ had thrombocytopenia smaller than $100,000 / \mathrm{mm}^{3}$ and 4 with platelets less than $142,000 / \mathrm{mm}^{3}$ and above $100,000 / \mathrm{mm}^{3}$. The child presented with six treatment regimens and different antibiotics without clinical improvement. In the evolution of the child she developed cholestasis, jaundice becoming well and the levels of total and direct bilirubin were respectively: Day 08/11/2012: $15.58 \mathrm{mg} \%$ and $12.36 \mathrm{mg} \%$. Day 9/11/2012 despite negative serology for cytomegalovirus, was conducted PCR (polymerase chain reaction) of urine specimen which was identified genomic sequences of CMV (cytomegalovirus). From the result of the PCR was started treatment with ganciclovir at a dose of $5.0 \mathrm{mg} / \mathrm{kg} /$ day on $12 / 11 / 2012$, due to clinical severity. After this period the patient began to exhibit improved clinical response with reduction of ventilatory parameters and decreased jaundice: BT: $9.88 \mathrm{mg} \%$ and BD: $8.04 \mathrm{mg} \%$. An echocardiogram confirmed and patent ductus arteriosus 2.8 $\mathrm{mm}$, but there was no response to clinical measures.

\section{Discussion}

The spectrum of diseases causing neonatal cholestasis becomes intriguing problems in investigations. There are many causes, and the end result is the specific problem peculiar characteristics. For example, extrahepatic biliary atresia may be the result of viral infection leading to progressive obstruction, of the extrahepatic bile ducts with some degree of injury of the intrahepatic bile duct. This same sequence of injury with persistent viral infection may be responsible for sporadic (non-familial) as cases of neonatal hepatitis [13].

It is difficult to determine the frequency of cholestatic jaundice, ranging between 1:2500 and 1:5000 newborns. Intrahepatic cholestasis neonatal represents $2 / 3$ of cases of neonate cholestasis $[14,15]$. The most common causes of the disease are infections, including cytomegalovirus (CMV) and the situation of a newborn patient with cholestasis, one should think of CMV.

The specific treatment for cytomegalovirus is ganciclovir, which is a synthetic nucleoside analogue 2'-Deoxyguanine that inhibits replication of herpes viruses both in vitro and in vivo. It was observed that patients with cholestatic hepatitis have improved levels of direct bilirubin, AST (aspartate aminotransferase), ALT (alanine aminotransferase), GGT (Gamma glutamyl transpeptidase) and ALP (alkaline phosphatase) using drug. In addition to this, another drug used to treat immune compromised has shown good results, foscarnet, which reduces viral replication by inhibiting viral DNA polymerase enzyme [6].

Children treated with ganciclovir may develop neutropenia, but in three laboratory assessments during the use of ganciclovir child in this study, none of the blood counts was observed neutropenia, so during this treatment is also important to monitor leukocyte counts and absolute neutrophil. These changes are drug-dependent and often no need for discontinuation of medication [16]. Ganciclovir may also cause nephrotoxicity and liver enzyme abnormalities, tremors, changes at the infusion site (phlebitis), nausea, vomiting, rash and fever [17].

However, cost-effective, use of ganciclovir can prevent hearing loss, and developmental changes and improvements in pictures of cholestatic hepatitis. The usual dose of $10 \mathrm{mg} /$ $\mathrm{kg}$ /day of ganciclovir is divided into two doses administered intravenously over 2 to 4 weeks for 60 minutes [16] according to the severity of the disease. Currently researchers suggest shorter treatment time in remission EV with ganciclovir for 21 days, followed by valganciclovir oral dose of 15 to $18 \mathrm{mg} / \mathrm{Kg}$ single daily dose (USA) twice daily for 21 days, indicated for the treatment and prophylaxis of CMV retinitis in immune compromised patients [17].

\section{Place of the Study}

Neonatal intensive care unit of University Hospital of the Federal University of Mato Grosso do Sul, Campo GrandeMS. 


\section{Competing Interests}

None declared.

\section{Funding}

FUNDECT, PROP-UFMS, CAPES, CNPQ, FAPEMIG.

\section{References}

1. Ahlfors K, Ivarsson SA, Harris S. Report on a long-term study of maternal and congenital cytomegalovirus infection in Sweden. Review of prospective studies available in the literature. Scand J Infect Dis. 1999;31(5):443-457.

2. Stagno S, Britt B. Cytomegalovirus. In: Remington JS, Klein JO, Wilson CB, Baker CJ, editors. Infectious diseases of the fetus and newborn infant. 6th ed. Philadelphia: Elsevier Saunders; 2006. p. 740-81..

3. Revello MG, Zavattoni M, Baldanti F, Sarasini A, Paolucci S, Gerna G. Diagnostic and prognostic value of human cytomegalovirus load and IgM antibody in blood of congenitally infected newborns. J Clin Virol. 1999;14(1):57-66.

4. Fowler KB, Boppana SB. Congenital cytomegalovirus (CMV) infection and hearing deficit. J Clin Virol. 2006;35(2):226-231.

5. Jones, C.A. Congenital cytomegalovirus infection. Curr Prob Pediatr Adolesc Health Care. 2003; 33: 65-100.

6. Kimberlin DW, Lin CY, Sanchez PJ, Demmler GJ, Dankner W, Shelton M, Jacobs RF, et al. Effect of ganciclovir therapy on hearing in symptomatic congenital cytomegalovirus disease involving the central nervous system: a randomized, controlled trial. J Pediatr. 2003;143(1):16-25.

7. Lackner A, Acham A, Alborno T, Moser M, Engele H, Raggam RB, Halwachs-Baumann G, et al. Effect on hearing of ganciclovir therapy for asymptomatic congenital cytomegalovirus infection: four to 10 year follow up. J Laryngol Otol. 2009;123(4):391-396.
8. Oliver SE, Cloud GA, Sanchez PJ, Demmler GJ, Dankner W, Shelton M, Jacobs RF, et al. Neurodevelopmental outcomes following ganciclovir therapy in symptomatic congenital cytomegalovirus infections involving the central nervous system. J Clin Virol. 2009;46(Suppl 4):S22-26.

9. Michaels MG, Greenberg DP, Sabo DL, Wald ER. Treatment of children with congenital cytomegalovirus infection with ganciclovir. Pediatr Infect Dis J. 2003;22(6):504-509.

10. Schleiss MR, McVoy MA. Overview of congenitally and perinatally acquired cytomegalovirus infections: recent advances in antiviral therapy. Expert Rev Anti Infect Ther. 2004;2(3):389-403.

11. Puliyanda DP, Silverman NS, Lehman D, Vo A, Bunnapradist S, Radha RK, Toyoda M, et al. Successful use of oral ganciclovir for the treatment of intrauterine cytomegalovirus infection in a renal allograft recipient. Transpl Infect Dis. 2005;7(2):71-74.

12. Ballard JL, Khoury JC, Wedig K, Wang L, EilersWalsman BL, Lipp R. New Ballard Score, expanded to include extremely premature infants. J Pediatr. 1991;119(3):417-423.

13. Dellert SF, Balistreri WF. Neonatal cholestasis. In: Walker WA, Durie PR, Hamilton JR, Walker-Smith JA, Watkins JB, et al., editors. Pediatric gastrointestinal disease. 3nd ed. Canada: B.C. Decker; 2000. p. 880-894.

14. Fischler B, Papadogiannakis N, Nemeth A. Aetiological factors in neonatal cholestasis. Acta Paediatr. 2001;90(1):88-92.

15. Yachha SK, Sharma A. Neonatal cholestasis in India. Indian Pediatr. 2005;42(5):491-492.

16. Caldes A, Gil-Vernet S, Armendariz Y, Colom H, Pou L, Niubo J, Llado L, et al. Sequential treatment of cytomegalovirus infection or disease with a short course of intravenous ganciclovir followed by oral valganciclovir: efficacy, safety, and pharmacokinetics. Transpl Infect Dis. 2010;12(3):204-212.

17. Yousfi MM, Douglas DD. Other Hepatitis Viruses. In: Zakim B. Hepatology. 4nd ed. Philadelphia: Saunders; 2003. pp. 1063-1072. 